\title{
FEM simulation of the endlessly long fluid filled canal due to horizontal ground motion
}

\author{
Kamila Kotrasová \\ The Technical University of Kosice, Kosice, Slovak Republic \\ E-mail: kamila.kotrasova@tuke.sk
}

Received 15 March 2019; accepted 1 April 2019

DOI https://doi.org/10.21595/vp.2019.20660

Check for updates

Copyright $(2019$ Kamila Kotrasová. This is an open access article distributed under the Creative Commons Attribution License, which permits unrestricted use, distribution, and reproduction in any medium, provided the original work is properly cited.

\begin{abstract}
The dynamic behavior of fluid filling in moving containers is a phenomenon that has attracted the attention lot of scientists. The liquid in an arbitrary shaped container under external excitations exerts the hydrodynamic pressure that with hydrostatic pressure acting together onto walls and bottom of container. The knowledge of the hydrodynamic fluid response on the solid domain of structure contributes to reliability and earthquake resistance of liquid-containing systems. This paper presents the possibility of simulation endlessly long fluid filled the rectangular tank - channel due to an action of horizontal ground motion. The Finite Element Method was used for simulation of this problem. One computational model uses FEM formulation ALE FSI and two models simulate only the solid domain by FEM and fluid effect due to horizontal ground motion is simulated by fluid-quasistatic hydrodynamic pressure given by Eurocode 8 and Indian standard.
\end{abstract}

Keywords: canal, ground motion, FEM.

\section{Introduction}

The dynamic behavior of fluid filling in moving containers is a phenomenon that has attracted the attention of geophysicists, engineers and mathematicians [1]. Liquid in an arbitrary shaped container under external excitations exerts the hydrodynamic pressure causing onto walls and bottom of fluid filled container together with hydrostatic pressure [2]. The knowledge of hydrodynamic effect of fluid on liquid storage tanks during the movement of the earth surface contributes to reliability and earthquake resistance of liquid-containing or liquid-transporting systems [11]. The design of containers loaded of earthquake is encouraged by various codes [3] IBC 2000, ACI codes, AWWA codes, API, Eurocode 8, NZSEE and Indian code. In this paper will be analyzed seismic response of rectangular infinitely long tank - canal by using of Eurocode 8 [4] and Indian standards [5] by simulating of Finite Element Method (FEM) with comparing of numerical solution using of FEM the Arbitrary-Lagrangian-Eulerian (ALE) formulation with the two way Fluid-Structure Interaction (FSI) techniques for simulation of the interaction between the structure and the fluid at the common boundary [6].

\section{Seismic effect of fluid on channel}

The solving of the Laplace equation for the motion of liquid contained in rigid channels can be stated as the two segregated contributions [7,8]. They are called "impulsive", and "convective", respectively [9]. The "impulsive" component of the solution accepts the boundary conditions at the canal walls and the canal bottom but gives zero pressure at the original position of the fluid free surface in the static situation [10]. It is not correct, because the solution not taken the presence waves of the dynamic liquid response [11]. The second "convective", called "sloshing" unaccepted the boundary conditions at the canal walls and the canal bottom, but gives the correct equilibrium condition at the free fluid domain surface [12].

The considered a rectangular shallow founded infinitely long canal, having the width $2 L$, with uniform thickness walls [13]. Rectangular canal was filled with liquid to the height $H$. Thestorage structure is excited by a horizontal ground motion in the $y$-direction, Fig. 1 [14]. 
The Laplace equation of rectangular channel whose walls can be considered as rigid that is excited by the horizontal ground motion can be given in the Eq. (1) [15]. The total hydrodynamic pressure is given as absolute summation of an impulsive and a convective contribution [16]:

$p(z, t)=p_{i}(z, t)+p_{c}(z, t)$.

The impulsive component can be expressed by:

$p_{i}(z, t)=q_{1}(z) \rho L A_{g}(t)$,

where the function $q_{i}(z)$ [17] gives the variation of impulsive pressure in direction of the height, $L$ is the half of the channel width in the direction of the seismic loading, $\rho$ is mass fluid density. The time-history dependent ground acceleration $A_{g}(t)$ gives the time dependence of the pressure $p_{i}(z, t)$ in Eq. (2) [19].

The hydrodynamic convective pressure component can be obtained by the summation of modal sloshing terms, each one having a different variation in time [20]. The decisive contribution for rectangular channel is the first mode:

$p_{c 1}(z, t)=q_{c 1}(z) \rho L A_{1}(t)$

where $A_{1}(t)$ is the accelaration response function of a simple oscillator with frequency of the first fundamental mode with the appropriate value of damping, when is subjected to the input acceleration $A_{g}(t)$ [21]. The function $q_{c 1}(z)$ [22] gives the distribution of impulsive pressure along the height for dominant first mode [23].

The first sloshing mode period of oscillation o is:

$T_{c 1}=\sqrt{\left(\frac{L}{g}\right) /\left(\frac{\pi}{2} \tanh \left(\frac{\pi}{2} \frac{H}{L}\right)\right)}$.

\section{Numerical experiment and conclusion}

The shallow founded reinforced concrete rectangular infinitely long fluid transporting canal is considered in presented numerical experiment, as seen in Fig. 1, without roof slab structure covered the channel.

The material characteristics of channel structure with Young's modulus $E=37 \mathrm{GPa}$, mass density $\rho=2550 \mathrm{~kg} / \mathrm{m}^{3}$ and Poisson ratio $v=0.20$. The mass density of fluid $\left(\mathrm{H}_{2} \mathrm{O}\right)$ filling is $\rho_{w}=1000 \mathrm{~kg} / \mathrm{m}^{3}$.

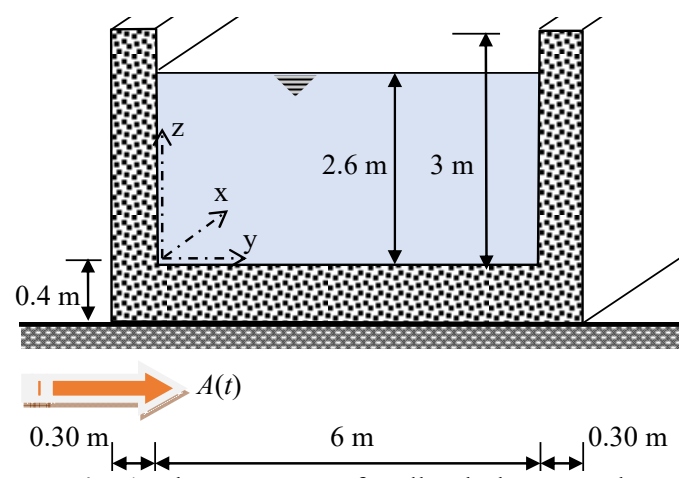

Fig. 1. The geometry of endlessly long canal 
Response of open top liquid filled concrete canal was worked by using of FEMALE FSI formulation. This model was signed "Model FSI". The solid walls and base of the canal was modelled by using 2D SOLID finite element with plain strain definition and the fluid inside the canal was modelled by using 2D FLUID finite elements under plain strain definition.

The alternative "quasistatic" approach of numerical simulation by using of FEM was considered by using of software ADINA too. In these approaches only solid domain of structure - the base and walls of the canal were modelled by plain strain definition of 2D SOLID finite element. The effect of fluid was simulated classically as the static loading by hydrostatic pressure together with hydrodynamic pressure.

The model "Model EC" use the hydrodynamic pressure distribution given by recommendation of Eurocode 8 [5]. The model "Model IS" use the hydrodynamic pressure distribution given by recommendation of Indian standards (IS) [6]. The horizontal ground motion given is given by the accelerogram of the earthquake Loma Prieta, California, 1989 [24]. The impulsive period $T_{i}=0.041 \mathrm{~s}\left(f_{i}=24.52 \mathrm{~Hz}\right)$ and $5 \%$ damped elastic response spectrum $S_{a}\left(f_{i}\right)=1.87 \mathrm{~m} / \mathrm{s}^{2}$ is used for calculation of the effect of tank solid inertia and the hydrodynamic impulsive pressure. The first convective frequency $f_{c 1}=0.382 \mathrm{~Hz}$ and $0.5 \%$ damped elastic response spectrum $S_{a}\left(f_{c 1}\right)=0.595 \mathrm{~m} / \mathrm{s}^{2}$ is used for calculation of hydrodynamic convective pressure.

The comparison of peak values of distribution of hydrodynamic impulsive pressure along the canal wall height by recommendation of EC8-4 and IS it is seen in Fig. 2(a). The Fig. 2(b) presents the comparison of peak values of distribution of hydrodynamic convective pressure along the tank wall height by recommendation of EC8-4 and IS.

The comparison of peak values of horizontal deformation of solid domain of canal, the peak Von Mises pressure in solid domain of channel and the peak fluid pressure for all three models were documented in Table 1.

Table 1. Seismic response of canal

\begin{tabular}{|l|c|c|c|}
\hline \multicolumn{1}{|c|}{ Model } & FSI & EC & IS \\
\hline The peak horizontal deformation of solid domain of canal in $[\mathrm{mm}]$ & 0.841 & 1.072 & 1.088 \\
\hline The peak Von Mises pressure in solid domain of canal in $[\mathrm{MPa}]$ & 2.258 & 2.555 & 2.556 \\
\hline The peak fluid pressure $[\mathrm{kPa}]$ & 29.951 & 29.176 & 29.456 \\
\hline
\end{tabular}

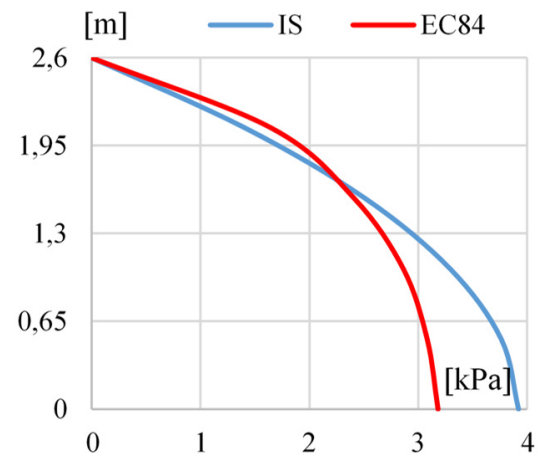

a)

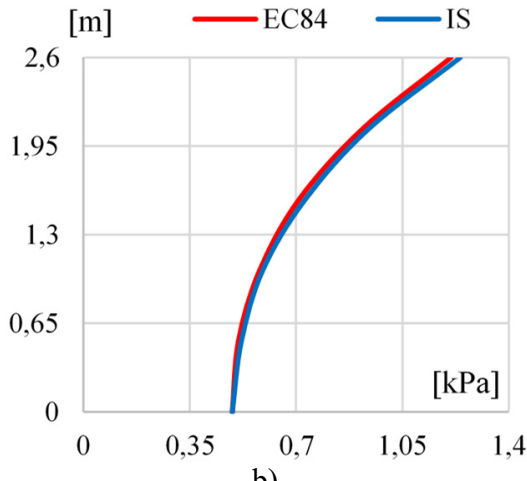

b)

Fig. 2. a) The comparison of peak values of hydrodynamic impulsive pressure distribution along the canal wall height by recommendation of EC 8-4 and IS, b) the comparison of peak values of hydrodynamic convective pressure distribution along the tank height by recommendation of EC8-4 and IS

\section{Acknowledgements}

This work was supported by the Scientific Grant Agency of the Ministry of Education of Slovak Republic and the Slovak Academy of Sciences the Project VEGA 1/0374/19. 


\section{References}

[1] Ibrahim R. A. Liquid Sloshing Dynamics: Theory and Applications. Cambridge University Press, New York, 2005.

[2] Abramson H. N. The Dynamic Behavior of Liquids in Moving Containers. NASA SP-106, National Aeronautics and Space Administration, Washington, D. C., 1966.

[3] Kotrasová K., Kormaníková E. The study of seismic response on accelerated contained fluid. Advances in Mathematical Physics, Vol. 2017, 2017, p. 1492035.

[4] Jaiswal O. R., Rai D. C., Jain S. K. Review of seismic codes on liquid-containing tanks. Earthquake Spectra, Vol. 23, Issue 1, 2007, p. 239-260.

[5] IITK-GSDMA Guidelines for Seismic Design of Liquid Storage Tanks - Provisions with Commentary and Explanatory Examples. Kanpur, Indian Institute of Technology Kanpur, 2005.

[6] EN 1998-4: 2006 Eurocode 8. Design of Structures for Earthquake Resistance. Part 4: Silos, Tanks and Pipelines. CEN, Brussels, 2006.

[7] Housner G. W. Dynamic pressures on accelerated fluid containers. Bulletin of the Seismological Society of America, Vol. 47, Issue 1, 1957, p. 15-35.

[8] Kotrasova K. Sloshing of liquid in rectangular tank. Advanced Materials Research, Vol. 969, 2014, p. 320-323.

[9] Jendzelovsky N., Balaz L. Numerical modeling of cylindrical tank and compare with experiment. In: Applied Mechanics and Materials, Vol. 617, 2013, p. 148-151.

[10] Kotrasova K., Grajciar I. Dynamic analysis of liquid storage cylindrical tanks due to earthquake. Advanced Materials Research, Vol. 969, 2014, p. 119-124.

[11] Michalcova V., Lausová L. Numerical approach to determination of equivalent aerodynamic roughness of industrial chimneys. Computers and Structures, Vol. 207, 2017, p. 187-193.

[12] Kralik J., Kralik J. jr. Probability assessment of analysis of high-rise buildings seismic resistance. Advanced Materials Research, Vol. 712, Issue 715, 2013, p. 929-936.

[13] Major M., Major I. Analysis of the mechanical wave in the composite made of sandstone and rubber. Procedia Engineering, Vol. 190, 2017, p. 223-230.

[14] Kotrasova K. Dynamic Behavior of Fluid Rectangular Container, International Journal of Mechanics. Vol. 12, 2018, 170-177.

[15] Krejsa M., Janas P., Krejsa V. Software application of the DOProC method. International Journal of Mathematics and Computers in Simulation, Vol. 8, 2014, p. 121-126.

[16] Kotrasova K. Study of hydrodynamic pressure on wall of tank. Procedia Engineering, Vol. 190, 2017, p. 2-6.

[17] Malhotra P. K., Wenk T., Wieland M. Simple procedure for seismic analysis of liquid-Storage tanks. Structural Engineering International, Vol. 3, 2000, p. 197-201.

[18] Melcer J. Experimental verification of an assumption. 52nd International Conference on Experimental Stress Analysis, 2014.

[19] Kotrasová K., Kormaníková E. Response of endlessly long shipping channel due to earthquake. MATEC Web of Conferences, Vol. 107, 2017, p. 00068.

[20] Kuklík P. Preconsolidation, Structural Strength of soil, and its effect on subsoil upper structure interaction. Engineering Structures, Vol. 33, 2011, p. 1195-1204.

[21] M. Zmindak M., Grajciar I. Simulation of the aquaplane problem. Computers and Structures, Vol. 64, Issues 5-6, 1977, p. 1155-1164.

[22] Kotrasová K., Kormaníková E. Hydrodynamic analysis of fluid effect in rigid rectangular tank due to harmonic motion. Key Engineering Materials, Vol. 635, 2015, p. 147-150.

[23] Tvrda K. RSM method in probabilistic analysis of the foundation plate. Procedia Engineering, Vol. 190, 2017, p. 516-521.

[24] Kotrasová K. Grajciar I., Kormaníková E. A case study on the seismic behavior of tanks considering soil-structure-fluid interaction. Journal of Vibration Engineering and Technologies. Vol. 3, Issue 3, 2015, p. 315-330. 